subjects, is sure to prove of great service to advanced students. A valuable chapter on applied electricity is introduced, in which is a welcome section on the harmonic analysis of curves. The chapter on electric oscillations is one of the best in the volume. Prof. J. Zenneck's photographs of oscillatory discharges, two of which are here reproduced by the courtesy of the publishers, are excellent, as are the descriptions of the laboratory experiments that may be carried out in illustration of various branches of the subject. In a footnote to p. 444 is found a reference to the fact that the ratio of the electromagnetic to the electrostatic unit of charge has the dimensions of a velocity, followed by the startling statement: "The theory of electrical dimensions is otherwise of little interest." In view of the practical advantage to be gained by testing the dimensions of the terms of an equation and the stress laid recently on the principle of similitude or dynamical similarity, such an attitude cannot be justified.

In the chapter on the conduction of electricity through gases the author is scarcely fair to research carried out in this country. The corpuscular view of the kathode rays seems to have been advanced first by Varley in $187 \mathrm{I}$, and the investigations of $\operatorname{Sir} W$. Crookes surely deserve further description. In the account of the measurement of the ratio of the charge to the mass for the kathode particles Mr. Pidduck is less than just to the work of Schuster described in his second Bakerian lecture (189o) and to the experiments of Sir J. J. Thomson shown in a lecture delivered before the Royal Institution (Electrician, May 21, I897). Kaufmann's paper was communicated to the Annalen on the same date. Wiechert's earlier experiments, "which did not go beyond the previous work of other observers" ("The Progress of Physics," Schuster, p. 68, I9I I), were described in a lecture delivered on January 7, I897. The experiments of Richardson and Compton in America on the photo-electric effect were carried out almost at the same time as those of Hughes at Cambridge. Millikan has just shown that it is possible to get very accurate values for 'Planck's constant, ' $h$, by the use of this method. A useful summary of fundamental physical quantities is given on p. $5^{13}$. The name "Boltzmann's constant" is assigned by the author to the constant of molecular energy, $\alpha$. It is usual to give this name to the entropy constant, $k$, which has a value $\frac{2}{3} \alpha$.

The concluding chapters deal with radioactivity, as exhibited by radium and its derivatives, and the mathematical theory of electrons. The illustrations include a number of C. T. R. Wilson's remarkable cloud photographs showing the tracks of ionising particles in gases.

$$
\text { NO. } 2445 \text {, VOL. } 98]
$$

H. S. A.

\section{EGYPTIAN ASTRONOMY AND THE ZODIAC}

IN a recent number of the Bulletin de l'Institut Français d'Archéologie Orientale (cxii.) of Cairo, M. Georges Daressy, one of the foremost among French Egyptologists, treats of the knowledge of the constellations in ancient Egypt. His article is entitled "L'Egypte Céleste," by which words he means the duplication of the geography of the Nile valley into the sky, for the priests mentally projected another Egypt into the northern heavens. By a kind of symbolic celestial geography the daily solar journey was considered as a descent or voyage of the sun upon a river, the duplicate of the Nile, but situate in the firmament.

This conception having been evolved, to render

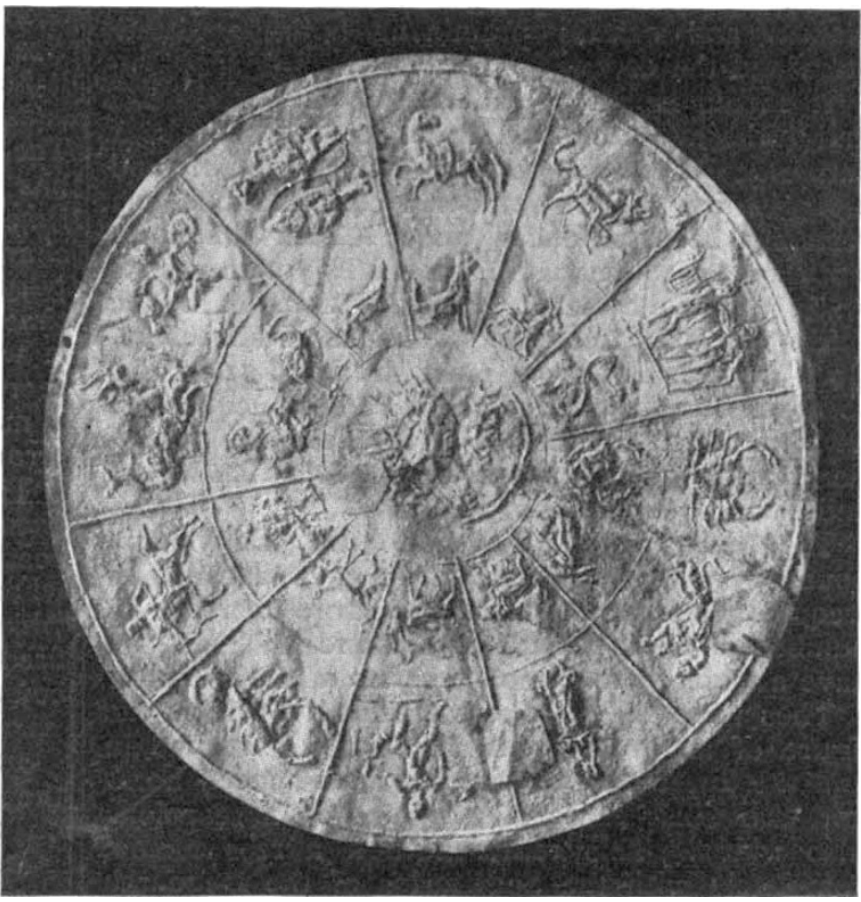

Double zodiac of the French Archæological Institute at Cairo.

the allegory geographically complete, it became necessary to have a series of "nomes," or counties, alongside the celestial river upon the banks, the district deities of which should correspond with those of similar sites through which the terrestrial Nile wended its way: For this purpose they selected the path of the ecliptic and identified that with the Nile's course. Precisely as each Nilotic "nome" possessed its own deity with his, or her, special totem symbol, so the Egyptian "wise men" provided parallel deity figures for their celestial river upon which the sun voyaged. With this object they adopted the zodiacal signs-the decans, the planets, and various constellations-because they required stellar associations, not only for the forty-two 
"nomes," but also for more than one temple, or important shrine, and its attendant city in many of the "nomes."

The event which induces M. Daressy to publish the fruits of his erudition upon this subject is the publication by him of a bronze zodiac with a series of two rows of twelve figures, the outer zone being the familiar zodiacal signs, and the inner, twelve animal symbols, attributable, Egyptologists think, to the twelve forms or phases assigned to the sun during his twelve hours' journey. These, in the earthly Egyptian gazetteer, are assigned to twelve of the twenty districts of Lower Egypt. This newly found double zodiac is very valuable for the explanation it affords of the symbols of the constellations upon the Denderah zodiac, because all these figures are intermingled in the large central circular disc, mixed up with deity figures representing the planets and certain prominent high-magnitude stars and the decans.

It should be stated that the zodiacs designed, and hitherto found, in Fgypt are not of great antiquity. The arrangement of their symbols and of figurative objects for some constellations has certainly been produced under Greek influence. They appear to emanate from the Egyptian priests uniting their old stellar figure mythologies to the astronomical astrology of the Alexandrian school. Both parties, however, must at the date of the composition of these zodiacs have been acquainted with the Chaldean science of the heavens, derivations from which appear in the Old Testament and early Greek classics and art.

The deity symbols upon the Babylonian boundary stones are almost always astral and frequently zodiacal. Since the large increase in number of these monuments found at Susa, we have a much more complete series of the symbols.

Thus upon the stele of Melishipak we have the figure of an archer with the upper part human and the lower part that of a double-headed horse and two tails; those of a horse and a scorpion; also wings, This representation agrees almost completely with the Sagittarius of the Denderah zodiac, and with this Sagittarius the scorpion is associated in both cases.

This assimilation of Mesopotamian astronomy is identical with the adoption by the Egyptians of several Babylonian legends of the gods into Egyptian mythology. These exploits were foisted upon the deeds of Egyptian deities. For example, the Izdubar (Hercules) legends were in some cases introduced into the conflicts of Horus.

The parallels between terrestrial Egyptian geography and the places of the stars must, however, have been very old in Egypt, though not anterior to the era of Menes. M. Daressy ingeniously explains the principles upon which these were arranged, and henceforth Egyptologists will trace in the primitive texts allusions to them and decide approximately when they were invented. The favourite constellations other than the zodiac were the circumpolar stars, because they never set and so were symbolic of eternity.

NO. 2445 , VOL. 98$]$
In addition to the famous zodiac from Denderah, now in the Louvre, we have, among others, the new one at Cairo, the planisphere and tableaux carved on the hypostyle hall at Denderah, copies of others once at Esneh and Erment, and the coffin of Hern-netch-tep in the British Museum.

JOSEPH OFFORD.

\section{THE PREVENTION OF COLLISION AT $S E A .^{1}$}

PROF. JOLY proposes, in the work before us, that sound, which travels at different rates through different fluids, should be utilised for navigational purposes as well as for the prevention of collision. The rate of travel of sound through air-viz. Iogo $\mathrm{ft}$. per sec. at a temperature of $32^{\circ} \mathrm{F}$. (zero C.), or I roo ft. per sec. at a temperature of $52^{\circ}$ F. (II I C.)-has long been utilised in H.M. naval surveying service for measuring bases in places where it is not possible to land, owing to the coast being covered with mangrove growth. The system in use is to fire a small mortar which has a plug driven in its muzzle and to note the time which elapses between the flash of the discharge and the report of the mortar. For this purpose a chronometer watch which beats five times for every two seconds of time is used, and it will be evident that each beat of the watch represents $440 \mathrm{ft}$., so that if the observer makes a mistake in counting the beats a corresponding error will be the result in the length of the base.

This method of ascertaining distance has also been used to ascertain the distance off a cliffy coast when sailing along it. In H.M.S. Actcoon, when sailing along the coast of Russian Tartary, which has very few distinctive marks, a gun was fired at intervals and the beats of the watch counted until the echo was heard. Half the time elapsed gave the distance off.

In the case of sound travelling through water the rate is much more rapid, and that rate depends on temperature as well as on the density. In river water the rate is $47 \mathrm{I} 4 \mathrm{ft}$. per sec. at a temperature of $55^{\circ} \mathrm{F}$. $\left(13^{\circ} \mathrm{C}\right.$.), and of $50 \mathrm{r} 3 \mathrm{ft}$. per sec. at a temperature of $86^{\circ} \mathrm{F}$. $\left(30^{\circ} \mathrm{C}\right.$. $)$, whilst in sea-water, at a temperature of $68^{\circ} \mathrm{F} .\left(20^{\circ} \mathrm{C}.\right)$, its rate is $476 \mathrm{r} \mathrm{ft}$. per sec., but where the specific gravity. of the water is increased, as in the Mediterranean or Red Sea, the time will be different. In thick weather, therefore, when the flash of a gun cannot be seen, the distance off can be ascertained by noting the number of beats between the receipt of a sound travelling through water and one through the air, provided they are emitted simultaneously. This difference is 4.25 secs. for each nautical mile the observer is distant from the point where the sound is emitted, or 10.63 beats of the watch per mile.

In a vessel fitted to send or receive radiotelegraphic messages, if a signal be sent simultaneously with the sound signals it is equal to seeing the flash of the gun. If the number of 1 "Synchronous Signalling in Navigation." Py Prof. J. Joly. Pp. is.. (London: T. Fisher Unwin Lid., Igr6.) Price $3 s .6 a$. net. 